\title{
Article \\ Identifying the Potential of RFID in Disaster Healthcare: An International Delphi Study
}

\author{
Samaneh Madanian * (D) and Dave Parry
}

check for updates

Citation: Madanian, S.; Parry, D. Identifying the Potential of RFID in Disaster Healthcare: An International Delphi Study. Electronics 2021, 10, 2621. https://doi.org/10.3390/ electronics10212621

Academic Editor: Giovanni Andrea Casula

Received: 6 October 2021

Accepted: 24 October 2021

Published: 27 October 2021

Publisher's Note: MDPI stays neutral with regard to jurisdictional claims in published maps and institutional affiliations.

Copyright: (c) 2021 by the authors. Licensee MDPI, Basel, Switzerland. This article is an open access article distributed under the terms and conditions of the Creative Commons Attribution (CC BY) license (https:/ / creativecommons.org/licenses/by/ $4.0 /)$.
Department of Computer Science and Software Engineering, School of Engineering, Computer and Mathematical Sciences, Auckland University of Technology (AUT), Auckland 1010, New Zealand; dave.parry@aut.ac.nz

* Correspondence: sam.madanian@aut.ac.nz

\begin{abstract}
Mainstream healthcare has been facing numerous challenges, and it is expected to see that these challenges become more severe and frequent when healthcare is dealing with disasters. This points to the necessity of utilising technologies to support healthcare and disaster managers in making quality decisions during chaotic and rapidly changing conditions in disaster situations. Therefore, in this research, the objective is to identify the role of RFID technology in healthcarerelated activities before, during, and after disasters in terms of application areas and phases of the disaster management cycle (DMC). A Delphi approach was used in this research. Two rounds of questionnaires were administered to a panel of experts to evaluate the actual and potential use of RFID applications for healthcare within DMC. The Delphi participants were the field experts in the areas of disaster management, disaster medicine, and information systems. Based on the Delphi results, RFID applications were seen to be most useful in the response and recovery phases of disasters. RFID was seen as being most helpful for health-related supply management and casualty information. There were concerns that privacy and security may be barriers to adoption and use. Other applications identified by this study include identifying and tracking medical resources (including clinicians and first responders) and their accurate coordination in the response missions, determining idle resources, and maximising their utilisation during response activities. In this research, 35 potential scenarios of RFID applications for healthcare purposes within DMC and Disaster e-Health (DEH) were evaluated with the Delphi participants. RFID technologies could play an important role in DMC and DEH to provide more reliable and timely information to support healthcare during disasters. Based on the research results, managing the supply chain emerged as a major RFID application for supporting disaster healthcare.
\end{abstract}

Keywords: disaster eHealth; RFID; disaster management; disaster medicine; disaster healthcare

\section{Introduction}

Disasters are an inseparable part of human life and have always afflicted civilisations. Even with the advent of new technologies, natural hazards are still causing environmental destruction, human suffering, and social and economic disruption. The source of disasters can be natural, man-made, or infectious diseases. However, regardless of the source, disasters impose huge pressure on medical and public health services.

Although health systems deal routinely with emergencies, disasters can be defined as events that surpass the normal capacity of systems and societies. During disasters, many decisions must be taken under uncertain conditions, all of which impose additional challenges and increase errors and mistakes and reduce efficiency. Healthcare has been incapable of responding properly to major disasters [1], and it is evident from the COVID-19 pandemic that healthcare systems are rarely disaster-ready.

These issues point to the necessity of utilising technologies to facilitate vital information integration and sharing among disaster responders and organisations. Moreover, providing precise and timely information can highly help both disaster managers and 
healthcare managers to make appropriate decisions. Different Information and Communication Technologies (ICT) have been employed to support healthcare in disasters, and Disaster e-Health (DEH) [2] has been recently defined by researchers as a systematic way of integrating e-health technologies into the Disaster Management Cycle (DMC) [3,4]. This integration can improve the performance of healthcare and the quality of the delivered services at the four stages of DMC: mitigation, preparedness, response, and recovery [5].

This paper focuses on Radio Frequency Identification (RFID) technology and aims to identify its potential applications for DEH and DMC. These applications have been inspired by their usage in healthcare, for example in emergency care [6], as it is postulated that RFID could play the same role in disaster situations. Furthermore, we need technologies that are interactive, easy to use, engaging, adaptable, and accessible for a diverse range of audiences [7], which is in line with RFID features and characteristics. RFID applications can support disaster management and medicine, and its systematic integration into DMC could prepare healthcare organisations for disasters, facilitate disaster response activities, and support disaster recovery and mitigation tasks.

\section{Research Background}

\subsection{RFID in Healthcare}

RFID systems consist of three main elements: tags, readers, and middleware. RFID tags uniquely identify objects, their location, determine changes in physical data, and send these data to a corresponding transponder [8]. Tags are classified into passive, active, and semi-passive categories, depending on the degree to which they are used to broadcast radio frequency energy from the readers to work [9]. RFID enables using data better, faster, and more accurately in indoor and outdoor environments, which distinguish it from other auto-identification technologies such as barcode and Global Positioning System (GPS). These features can better facilitate healthcare procedures. In addition, in comparison with recent technological evaluations in the field, such as Internet of Things (IoT) and sensors, RFID would be considered at its maturity stage. IoT only recently has obtained more clarity in its approaches and architectures [10], and its usage needs further people awareness [11].

Table 1 presents the potential advantages of RFID over other auto-identification technologies.

Table 1. RFID advantages (adapted from [12,13]).

\begin{tabular}{|c|c|}
\hline \multicolumn{2}{|c|}{ RFID Advantages } \\
\hline $\begin{array}{ll}\text { - } & \text { No ‘line of sight' requirements } \\
\text { - } & \text { High read rates } \\
\text { - } & \text { Read/Write capabilities } \\
\text { - } & \text { Data retrieved by handheld devices } \\
\text { - } & \text { Two-wayt-less communication } \\
& \end{array}$ & $\begin{array}{ll}\text { - } & \text { More automated reading } \\
\text { - } & \text { Large data capacity } \\
\text { - } & \text { Integue identification for tags } \\
\text { - } & \text { No human intervention } \\
\text { - } & \text { Higher accuracy }\end{array}$ \\
\hline
\end{tabular}

These features together with RFID enhancements and lower deployment costs have made RFID a promising tool in healthcare mainly due to its automatic identification and tracking capabilities [14]. Importantly, the dynamic rule encoding stored in tags has been introduced, and privacy protection of RFID has been significantly enhanced $[9,15]$.

RFID also reduces data entry errors, enhances efficiency and data accuracy, decreases time and cost, and reduces labour use. RFID offers various applications for healthcare ranging from tracking assets, patients, blood, and specimen bags to monitoring hospital wards, controlling infections, retrieving information, controlling drug distribution and pharmaceutical anti-counterfeiting.

Using RFID in healthcare could lead to cost saving due to business process optimisation [16] and decreasing patient mortality rate thanks to minimising human errors. RFID benefits are mainly classified into visibility, efficiency, asset management, security, customer service, collaboration, and cost reduction [17]. These benefits, directly or indirectly, result 
in enhancing efficiency, optimising patient safety, improving decision making, increasing the quality of caregiving and healthcare operations, and communication while decreasing cost and medical errors.

RFID deployment may help clinical industries improve patient safety [18]. This might be achieved through avoiding or reducing patient misidentification and medical errors in patient care including adverse drug effects, allergies, patient-medication mismatches, and medication dosage errors [16]. In addition, RFID could reduce the inherent human errors and consequent risks by automating the communication process and delivering relevant and accurate information to responsible organisations to employ medical resources rapidly and efficiently [13].

\subsection{RFID and Disaster Healthcare}

During disasters, medical systems are under exponential pressure, most routine procedures are disrupted, and many decisions must be taken under conditions of uncertainty that impose additional challenges and increase errors and mistakes and reduce efficiency. These issues necessitate utilising technologies to facilitate information integration and sharing among disaster responders and involved organisations. Providing precise and timely information can greatly help disaster and healthcare managers make appropriate decisions.

When there is high demand and pressure on healthcare systems and their resources, the entire system could be overwhelmed. In such circumstances, different technologies can be implemented and used in different disaster phases. However, having a single technology dealing with a wider range of objectives and purposes is more desirable due to the increased cost and complexity of several technologies implementations [19]. Furthermore, technologies' compatibility and integration may be an issue.

Adopting RFID within DMC was inspired by its current usage for normal and emergency care. Since using RFID provides efficient risk-free emergency care [6], it is postulated that it could play the same role in disaster situations. Therefore, its applications could be expanded to cover disaster management and medicine. In disaster management, the need for automation is quite significant, since disaster environments are harsh places prone to more accidents, and a bottleneck in a disaster situation is automatic information handling, not the lack of information or technology shortage [20]. Therefore, automation through decreasing the direct human intervention has the potential to prevent more after-disaster incidents by automating information handling, which can be achieved by employing RFID.

On the other hand, useful e-health tools in DMC should be interactive, easy to use, engaging, adaptable, and accessible for a diverse range of stakeholders [7]. People are less likely to use technologies that fail to correspond in any way with their daily lives or habits [21], especially in disaster situations. Therefore, suitable technology has the least interaction with human activities and minimises human interference and intervention with the whole system. Likewise, RFID has proved compatible with other technologies such as telecommunication, IT, and robotics [20], and it could be fully deployed in different phases of disasters with minimum human intervention:

(1) It covers vast healthcare-related areas ranging from population health and wellbeing to healthcare administrative activities;

(2) Its successful adoption in supply chains (SC) and medicine [22] raises the chance of RFID adoption for the same purposes within DEH and DMC;

(3) Its devices are cheap, small, and easy to use, which make them suitable and promising for disaster monitoring. These devices can operate in harsh environments, infected, extreme, and unsuitable working conditions, and uncontrollable climatic conditions [20];

(4) They can work independently without relying too much on infrastructures such as electricity or any other prerequisite technologies [20,23].

These unique features make RFID a capable technological tool for disaster management and medicine. Through automating processes and preparing information, it can aid disaster-related activities. According to the Task-Technology Fit (TTF) model, several 
factors make RFID utilisations distinguishable from similar technologies [22], especially in the disaster management field:

(1) For deployment, RFID is categorised under the 'Ease of Use' category; it means the complexity involved in the RFID utilisation and implementation is minimal, such as in training requirements and technical infrastructure.

(2) Localisation referring to assessing the physical location of objects or people that have a high priority in disaster management activities is covered by RFID.

(3) RFID can work seamlessly with other technologies; therefore, the compatibility aspect is also covered by RFID. This factor is the leading reason for the success of RFID adoption in health.

RFID-provided data regarding objects or people are accurate, reliable, available, and in real time. This enables authorities to make quality and timely decisions, especially in disaster response, and coordinate operations more effectively at local, regional, and national levels. This unified coordination leads to faster and better joint decisions [24] and can help authorities identify optimum preparation plans for future disasters by forecasting their capacity. These data also help in gaining a panoramic view of the disaster-affected areas to enhance medical readiness and real-time visibility of the disaster situation [15].

Owing to the complexity of healthcare operations during disasters, a high level of visibility is required, since medical personnel may have demands that exceed their capacity. RFID can support such requirements through information visibility [25], as RFID integrates object and information flow automatically, among disaster responders and other involved parties. Moreover, data storage and retrieval systems based on RFID might facilitate retrieving disaster site data when survivors are transferred to medical centres. These RFID data can be used to track and monitor, at the disaster site, conditions of disaster victims on a moment-to-moment basis for hours and days to give them quality care [26]. In such situations, different RFID applications can be useful ranging from patient tracking to "mobile data acquisition in the field, ambulance, and hospital to create a portable medical record" [27].

In a disaster, medical providers must prepare reports of the number of casualties, injury types, and medical needs for controlling managers. Since RFID systems enable automatic data acquisition and transfer in an easy and precise way, this may reduce the required response time by reducing the procedural delays in disaster management activities [20,22]. Since less time is spent on data gathering and transferring, the chance of saving a greater number of injuries increases, which results in enhancing the disaster response and post-disaster healthcare quality. RFID can be used to check available medical supplies to help save lives, in major disasters such as earthquakes [28], by allocating correctly and immediately the required resources for injuries' treatment.

RFID can track or monitor vulnerable citizens (people with chronic health conditions or disabilities, elderly, and children), evacuees, and dead bodies transferred from disaster sites to healthcare centres or other facilities during and after disasters. The real-time information about disaster survivors can be written on RFID tags to be accessible by authorities. This information can be casualties' personal information or basic medical information, such as blood type. Such data can support disaster managers and hospital managers to plan for allocating resources, transferring patients among facilities, and arranging inter-agency collaboration [29]. This information might be a valuable source for a better recovery phase, since it enables authorities to keep a record of casualties more easily. RFID provides easier and faster survivors' identification methods $[25,30]$ in the process of medical treatment when huge numbers of casualties are seeking treatment in disaster aftermaths. This application can provide a quick, easy, and reliable mechanism for identification and real-time tracking of the injured, responders, and volunteers [5].

RFID has also been applied to manage SC of disaster materials. It provides near real-time identification, tracking, and monitoring of materials distribution from suppliers to the disaster zone. It enables humanitarian organisations and others in doing 
so. Several studies have shown this application to be efficient, robust, reliable, and less labour-intensive [22,24,25,31,32].

RFID can integrate with different technologies. RFID was integrated with IoT sensors to reduce the implementation cost and energy consumption of tags while enhancing the coverage monitoring areas [23]. The IoT sensors acted as the tag (RFID) reader. In another study that was first undertaken by [15] and then enhanced by [33], RFID was integrated with Near Field Communication (NFC) and mobile phone devices to create a mobile triage (m-triage) system for carrying and communicating the triage information. The researchers believed this RFID-based triage system was quicker, more reliable, and could enhance the triage and, consequently, the quality of care. In Haiti, RFID was used with the In-Transit Visibility (ITV) network and satellite communications to track shipping containers and look up the shipment information [34] to streamline the humanitarian logistics.

\subsection{Research Gap}

Although healthcare operations have been improved and benefited from RFID technology in normal medicine, healthcare has demonstrated poor performance during and after disasters. Moreover, the unpredictable nature of most disasters and the need for making immediate and appropriate decisions have necessitated an organised approach that may benefit from RFID technology.

RFID can be used as supportive tools for disaster management and healthcare activities. However, despite increasing the usage of RFID and IoT in daily medicine and emergency care, their applications for disaster management are still low, irregular, and ad hoc. Different research studies have been conducted, and several RFID-based solutions have been proposed for disaster management and disaster healthcare, some of which have been covered in Section 2.2. Nevertheless, still there is a lack of systematic investigation and getting experts' views in identifying how and where RFID or IoT applications could be significant in disaster management or within DMC to address healthcare needs.

In this regard, this research was conducted to extract and evaluate the role of RFID for healthcare purposes in DMC for better coordinating efforts and ensuring population health and well-being before, during, and after disasters.

\section{Materials and Methods}

\subsection{Study Design}

Previous research undertook a scoping study in three fields of e-health, disaster management, and disaster medicine concerning DEH [3,4,12]. A list of scenarios and applications of RFID was also developed to evaluate the potential role and applications of RFID.

This research involves a Delphi study to refine the potential use of RFID technology within DMC and DEH. It involved two rounds of questionnaires, and the outcome was a list of scenarios of RFID applications for different disaster phases based on expert opinion.

Delphi is a systematic, interactive, and iterative method based around asynchronous electronic communication that is used to establish a reliable consensus among the panel of experts regarding a complex problem $[35,36]$.

\subsection{Delphi Method}

The overall structure of the Delphi method in this research is presented in Figure 1.

The selected experts must have knowledge of the area of the research [37]. In this research, a panel of 23 international experts from the Disaster eHealth Community of Interest group (DeCOI) [38] was contacted, out of which 11 members showed their interest and 9 agreed to participate in this Delphi study. DeCOI members are active researchers and practitioners and have experience and knowledge related to the fields; therefore, working with this group of experts could ensure the collection of a wide range of viewpoints as the input for this research. The experts had a multidisciplinary background with core 
knowledge of computer, information systems and IT, e-health, disaster management, and disaster medicine.

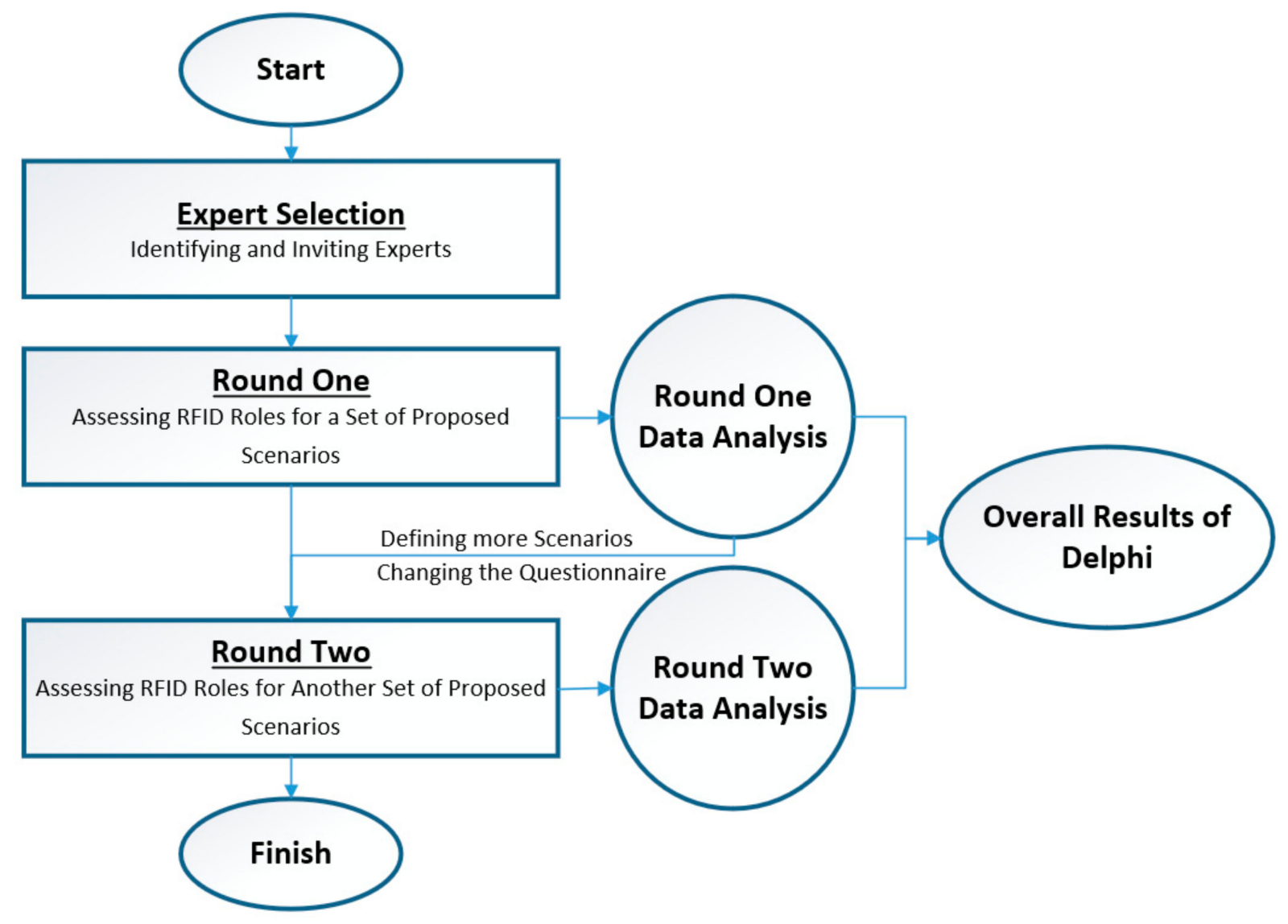

Figure 1. The overall structure of the Delphi method.

\subsection{Data Collection and Analysis}

This research was conducted in two rounds due to the small panel size, as it is believed that the minimum number of rounds required is two, particularly when the panel size is small [39-41]. A suitable number of Delphi participants is seven and a suitable panel size is between six and 12 members [42].

In each round, a questionnaire (Supplementary Files S1 and S2) was used as the data collection instrument. Both questionnaires consisted of open- and closed-ended questions and were sent to those panellists who accepted the invitation. The participants were asked for comments on the proposed scenarios and applications of RFID and to rank those applications for disaster management and disaster medicine purposes. Before starting the first round, to enhance the clarity, validity, and reliability of the questionnaire, design, and question type, a pilot test was conducted. For this purpose, the round 1 questionnaire was forwarded for review and feedback to one of the DECOI members who is an expert in disaster management, e-health, and the Delphi method. Additionally, the project information and consent form approved by AUT Ethical Committee (application \#17/111) were provided for the participants.

The first questionnaire was prepared based on the scoping findings by considering the research objectives and questions. A two-week deadline was set for responses. After the deadline, the researcher collected and analysed the responses.

The second-round questionnaire was prepared in light of reflection on the experts feedback in the first round and its related data analysis. The second questionnaire was submitted to the experts along with the first round report. In the second round, the panel also had the opportunity to refine and reconsider their original feedback if they wished 
or to develop new ideas. The overall framework of the conducted Delphi is presented in Figure 2.

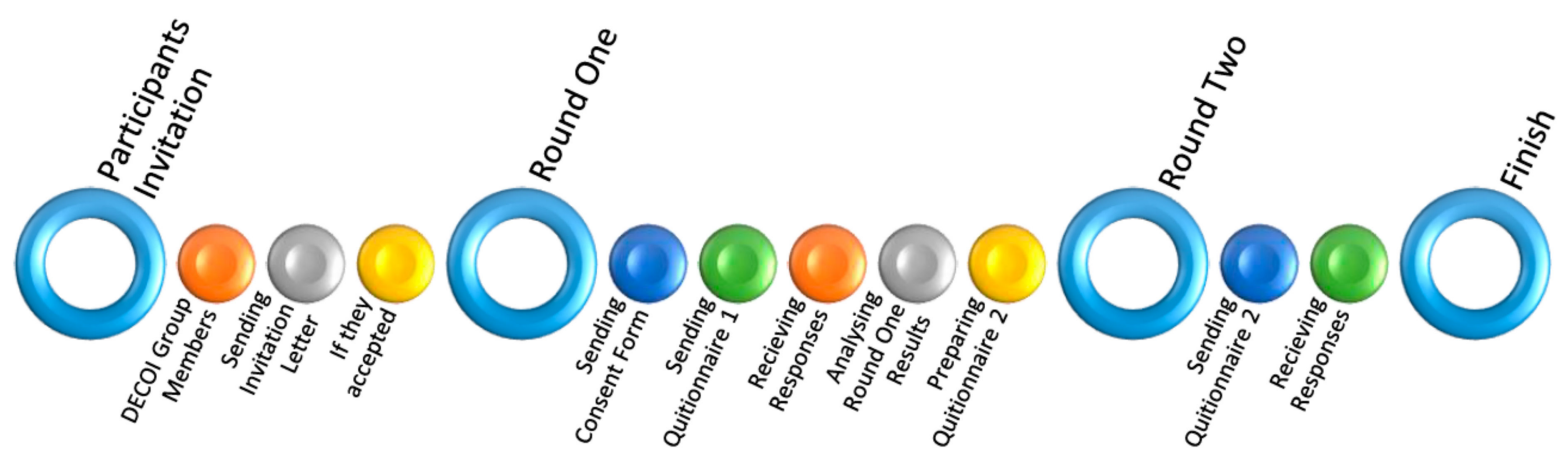

Figure 2. The adapted Delphi processes.

Reaching consensus among Delphi participants is of prime importance, and experts' feedback analysis and consensus measurement is a key element. These analysis and measurement methods vary significantly $[17,21]$, and both quantitative and qualitative analyses are common.

In both rounds, the experts' feedback and the level of agreement were analysed and measured using qualitative and subjective analysis. Furthermore, the frequency distribution method was used to measure consensus, as no significant difference was found in the central tendency and standard deviation. In frequency distribution, consensus will be achieved if at least $51 \%$ of all the responses fall in one category of the Likert scale [43-45]. In this regard, panellists who supported the RFID application for the proposed scenarios, by choosing to agree and strongly agree, were considered as one category, and the rest who disagreed with or were neutral regarding the RFID application were placed in another category.

Moreover, as recommended by [46], the internal consistency reliability of scales was measured and assessed for the validity of the given questionnaire, which refers to the construct consistency of the questionnaire. To test the reliability of the distributed questions, the Cronbach alpha was chosen for estimating the internal consistency of the questions. This method is one of the two most frequently reported methods [47] determining "the internal consistency or average correlation of items in a survey instrument to gauge its reliability" [48]. Its range is from 0 to 1 : the higher the figure, the better the reliability scale. A reliability coefficient of 0.7 is an acceptable score [49]. The results of the Cronbach alpha for questions in this research are depicted in Table 2.

Table 2. The results of the Cronbach alpha calculation.

\begin{tabular}{llll}
\hline \multicolumn{3}{c}{ Reliability Statistics } \\
\hline Round 1 & Phase & Cronbach's Alpha & Number of Items \\
\hline & Mitigation & 0.742 & 5 \\
& Preparedness & 0.756 & 4 \\
& Response & 0.797 & 4 \\
& Recovery & 0.862 & 5 \\
& Overall & 0.936 & 18 \\
\hline Round 2 & & \\
\hline & Mitigation & 0.750 & 4 \\
& Preparedness & 0.643 & 5 \\
& Response & 0.801 & 5 \\
& Recovery & 0.948 & 3 \\
& Overall & 0.873 & 17 \\
\hline
\end{tabular}




\section{Results}

Of the nine participants, eight completed the first round of Delphi. The experts were from New Zealand, Europe, and North America, the majority with doctorate degrees $(n=8)$, from academia $(n=9)$ with an academic and practical background in research $(n=6)$, disaster management $(n=2)$, healthcare $(n=1)$, and disaster medicine $(n=1)$, and the majority had 21 to 30 years of experience in the field $(n=5)$.

In both rounds, the questionnaires were aimed to determine the most applicable RFID role within DMC from the experts' viewpoint. In this regard, 18 potential RFID applications to address the identified challenges and requirements in [3] were explained through numerous scenarios categorised according to the disaster phases. The overall objective of all the proposed applications was facilitating disaster management activities and enhancing their effectiveness in DCM. The participants were asked to use the five-point Likert scale to rank the RFID applications regarding the applicability and desirability of having them for each proposed scenario. Furthermore, the participants were asked to comment on the application if they wish and name the other e-health technology(ies) that can support the same scenarios in more appropriate ways.

\subsection{Delphi Round 1}

Table 3 presents the obtained responses from the experts to the proposed RFID applications.

The analysis of the participants' comments showed that experts considered the RFID role as critical in the mitigation phase for the SC of resources and logistic services. The barriers and challenges for the other scenarios were as follows:

- The applicability of the solution for the multi-organisations;

- Limited regional localisation capabilities;

- Security and privacy of data.

Among these challenges, the biggest concern was security and data privacy, which was reflected in the score of the last scenario that dealt with patients' medical data.

\subsection{Delphi Round 2}

The experts' feedback in round 1 led to several major changes in terms of the applications of RFID for healthcare purposes by considering their concerns regarding security and privacy, out-building positioning, and accessibility of the technology at the time of the disaster. In this regard, in the second round, it was decided to examine another set of RFID applications scenarios in DMC and DEH scope to identify the tasks and activities that can benefit from RFID.

In this round, the questionnaire consisting of 17 scenarios was designed and sent to the same group of experts, but only seven replied. The responses to these scenarios are shown in Table 4. 
Table 3. Round 1 of RFID scenario applications in DMC and experts' responses.

\begin{tabular}{|c|c|c|c|c|c|}
\hline $\begin{array}{l}\text { Disaster } \\
\text { Phase }\end{array}$ & Scenario & Agree & $\begin{array}{l}\text { Neutral or } \\
\text { Disagree }\end{array}$ & $\begin{array}{l}\text { Response } \\
\text { Mean }\end{array}$ & Comment \\
\hline \multirow[t]{5}{*}{ Mitigation } & $\begin{array}{l}\text { Q1. Improving timely decision making in healthcare organisations including } \\
\text { reallocation of hospital resources and staff as the need arises by using RFID } \\
\text { capabilities such as automatic and real-time capturing the number and location of } \\
\text { medical and human resources. }\end{array}$ & 4 & 4 & 3.62 & $\begin{array}{l}{ }^{*} \text { Knowing where staff HR } \\
\text { resources are is important. }\end{array}$ \\
\hline & $\begin{array}{l}\text { Q2. Using RFID to automatically identify and capture healthcare } \\
\text { products/equipment by location and analyse usage patterns for each region to } \\
\text { predict future specific demands at the time of disaster and constantly monitor the } \\
\text { condition of healthcare centres. }\end{array}$ & 5 & 3 & 3.87 & $\begin{array}{l}{ }^{*} \text { Logistic services can be } \\
\text { significantly supported by } \\
\text { RFID technology when it } \\
\text { comes to usage and } \\
\text { demands of products and } \\
\text { equipment. }\end{array}$ \\
\hline & $\begin{array}{l}\text { Q3. Improving integration of information about increased demand on different } \\
\text { hospital sectors for the purpose of strategic decision making based on the real-time } \\
\text { and precise information captured by RFID tags. }\end{array}$ & 4 & 4 & 3.50 & \\
\hline & $\begin{array}{l}\text { Q4. Availability of victims' vital health information such as blood type, special } \\
\text { disease, or potential medication allergies and storing them on RFID tags and } \\
\text { protecting those valuable medical information from local disasters (unlike paper } \\
\text { records). }\end{array}$ & 5 & 3 & 4.00 & $\begin{array}{l}\text { * Associating the } \\
\text { technology to individual } \\
\text { information seems more } \\
\text { reliable in case of disaster. }\end{array}$ \\
\hline & $\begin{array}{l}\text { Q5. By recording medical/resource information on RFID tags electronically, precise } \\
\text { and real-time information is available to access and exchange across all medical } \\
\text { facilities that would improve and enable healthcare organisations to prepare for } \\
\text { emergency planning and cope with the next natural disaster. }\end{array}$ & 4 & 4 & 3.37 & \\
\hline \multirow[t]{2}{*}{ Preparedness } & $\begin{array}{l}\text { Q1. Through matching the population size of each region and their pattern of } \\
\text { health needs/demands and combining them with available hospital resources in } \\
\text { each region, we can be better prepared for disasters, and in this regard, RFID helps } \\
\text { us to keep track of available medical resources on a real-time basis to match with } \\
\text { the region's health demands. }\end{array}$ & 4 & 4 & 3.37 & \\
\hline & $\begin{array}{l}\text { Q2. Through automatic data capturing, RFID helps us to track and share } \\
\text { information on a regional healthcare centre and ensure the types and availability of } \\
\text { the medical resources. }\end{array}$ & 4 & 4 & 3.75 & \\
\hline
\end{tabular}


Table 3. Cont.

\begin{tabular}{|c|c|c|c|c|c|}
\hline $\begin{array}{l}\text { Disaster } \\
\text { Phase }\end{array}$ & Scenario & Agree & $\begin{array}{l}\text { Neutral or } \\
\text { Disagree }\end{array}$ & $\begin{array}{l}\text { Response } \\
\text { Mean }\end{array}$ & Comment \\
\hline & $\begin{array}{l}\text { Q3. RFID can be used to collect and utilise the critical information needed for a } \\
\text { Just-in-Time disaster plan as well as medical resource planning and the allocation } \\
\text { of new resources to depots. }\end{array}$ & 5 & 3 & 3.62 & \\
\hline & $\begin{array}{l}\text { Q4. Patients' medical data (important ones) should be pre-entered into Q4. RFID } \\
\text { tags so that data are immediately available at the time of disaster and can facilitate } \\
\text { disaster response mission. }\end{array}$ & 3 & 5 & 3 & \\
\hline \multirow{3}{*}{ Response } & $\begin{array}{l}\text { Q2. By using RFID tags (especially if people start using them from the previous } \\
\text { stages), since all the important health information is already available on their tags, } \\
\text { patients' care continuity would be guaranteed. }\end{array}$ & 2 & 6 & 3.12 & $\begin{array}{l}\text { * Associating the } \\
\text { technology to individual } \\
\text { information seems more } \\
\text { reliable in case of disaster. }\end{array}$ \\
\hline & $\begin{array}{l}\text { Q3. By using RFID tags during the response phase, victim identification and } \\
\text { tracking would be facilitated, which is time consuming and in certain } \\
\text { circumstances impossible through the traditional way. } \\
\text { Patients/medication misidentification and generally medicinal care can be very } \\
\text { vulnerable to different kinds of errors, even fatal ones; however, RFID can help } \\
\text { recognise the patients faster and more easily improve disaster victim tracking, } \\
\text { triage, patient care, and facility management; moreover, it can improve response } \\
\text { times, help present more effective 'first response', and thus reduce the mortality } \\
\text { rate. }\end{array}$ & 5 & 3 & 3.87 & $\begin{array}{l}\text { * Victim identification is } \\
\text { an important aspect where } \\
\text { RFID can help. } \\
\text { * As noted, victim } \\
\text { identification is important } \\
\text { (particularly for } \\
\text { evacuated/refugee } \\
\text { communities). }\end{array}$ \\
\hline & $\begin{array}{l}\text { Q4. By using RFID in the healthcare centres (especially from preparedness phase), } \\
\text { since responders have the real-time information of the available medical resources } \\
\text { on each healthcare centre, they are able to transport victims to the correct facility as } \\
\text { quickly as possible. }\end{array}$ & 4 & 4 & 3.87 & $\begin{array}{l}{ }^{*} \text { Information about } \\
\text { available resources gained } \\
\text { from RFID can help. }\end{array}$ \\
\hline
\end{tabular}


Table 3. Cont.

\begin{tabular}{|c|c|c|c|c|c|}
\hline $\begin{array}{l}\text { Disaster } \\
\text { Phase }\end{array}$ & Scenario & Agree & $\begin{array}{c}\text { Neutral or } \\
\text { Disagree }\end{array}$ & $\begin{array}{l}\text { Response } \\
\text { Mean }\end{array}$ & Comment \\
\hline Recovery & $\begin{array}{l}\text { Q1. By using RFID special tags, this opportunity is given to healthcare providers to } \\
\text { continuously monitor patients' health conditions, record and report vital signs, all } \\
\text { of which lead to optimising care management and reducing. }\end{array}$ & 5 & 3 & 3.75 & $\begin{array}{l}\text { * Limited feasibility of } \\
\text { RFID for this purpose; } \\
\text { also, data have to be read } \\
\text { directly from an RFID tag } \\
\text { located on the } \\
\text { citizen/victim; hence, } \\
\text { health data are not } \\
\text { available for remote } \\
\text { decision making. }\end{array}$ \\
\hline
\end{tabular}

Q2. By using RFID tags, since all the victim's health condition information before disaster and during response time is available on the tag, care disruption caused by disasters will be reduced, specifically for people with chronic disease, and continuity of care becomes possible.

Q3. Through the real-time monitoring capabilities of RFID, it would be possible to provide special advice to remote patients.

Q4. One of the tasks in this stage is fatalities identification, which can be improved through using RFID tags instead of paper ones that would facilitate further related procedures such as their location tracking and transferring to their relatives.

Q5. Since top managers have real-time and precise information about medical resources either used or in stock, they would be able to do medical planning for recovery more effectively and efficiently. 
Table 4. Round 2 of RFID scenario applications in DMC and experts' responses.

\begin{tabular}{|c|c|c|c|c|c|}
\hline $\begin{array}{l}\text { Disaster } \\
\text { Phase }\end{array}$ & Scenario & Agree & $\begin{array}{c}\text { Neutral or } \\
\text { Disagree }\end{array}$ & $\begin{array}{l}\text { Response } \\
\text { Mean }\end{array}$ & Comment \\
\hline \multirow[t]{3}{*}{ Mitigation } & $\begin{array}{l}\text { Q1. By equipping medical resources at each health centre with RFID tags, there could } \\
\text { be a potential for improvement in the quality and accuracy of the local, regional, and } \\
\text { even national medical resources assessment. }\end{array}$ & 3 & 3 & 3.83 & \\
\hline & $\begin{array}{l}\text { Q2. There is a potential to develop an information system based on RFID to } \\
\text { automatically gather medical resources data and integrate them into different levels } \\
\text { of local, regional, federal, and, finally, the disaster plan. }\end{array}$ & 3 & 3 & 3.83 & $\begin{array}{l}\text { * Potential is there, but we } \\
\text { need to be concerned with } \\
\text { the privacy and security of } \\
\text { personal health data at } \\
\text { least here in the US. }\end{array}$ \\
\hline & $\begin{array}{l}\text { Q3. At health centres, if medical resources, staff, and patients are equipped with RFID } \\
\text { tags, the current healthcare situation can be assessed by considering the available } \\
\text { medical resources, in-patients and their conditions, and pattern of medical resources } \\
\text { usage, for essential medical plan in relation to disaster vulnerability analysis. }\end{array}$ & 3 & 3 & 3.83 & $\begin{array}{l}\text { * Potential is there, but we } \\
\text { need to be concerned with } \\
\text { the privacy and security of } \\
\text { personal health data at } \\
\text { least here in the US. }\end{array}$ \\
\hline
\end{tabular}

Q4. One of the issues that hinders providing a proper disaster response plan is lack of research. One of the reasons is, during response due to overwhelming conditions and chaotic environments, limited statistics or reports are available regarding the quality and effectiveness of the response activities, shortage in medical supplies, etc However, if RFID is being utilised, this problem can be solved at least to some extent because of automatic data capturing. Therefore, for future disaster preparedness and response planning, past disasters can be referred to and reduce the probability of the same shortcoming appearing.

Q1. By tagging all medical resources, their pattern of usage (drug consumption) can be monitored automatically. Then, by sharing the identified pattern among

Preparedness healthcare centres, a warning system can be developed. This system has the potential to identify epidemic outbreaks and forecast epidemiology disasters by analysing medical resources usage patterns.

Q2. If all the medicine is tagged with RFID by the pharmaceutical companies, authorities might be able to match the inventory level of medicine with the population size in each region and their demands. Therefore, societies can be well 
Table 4. Cont.

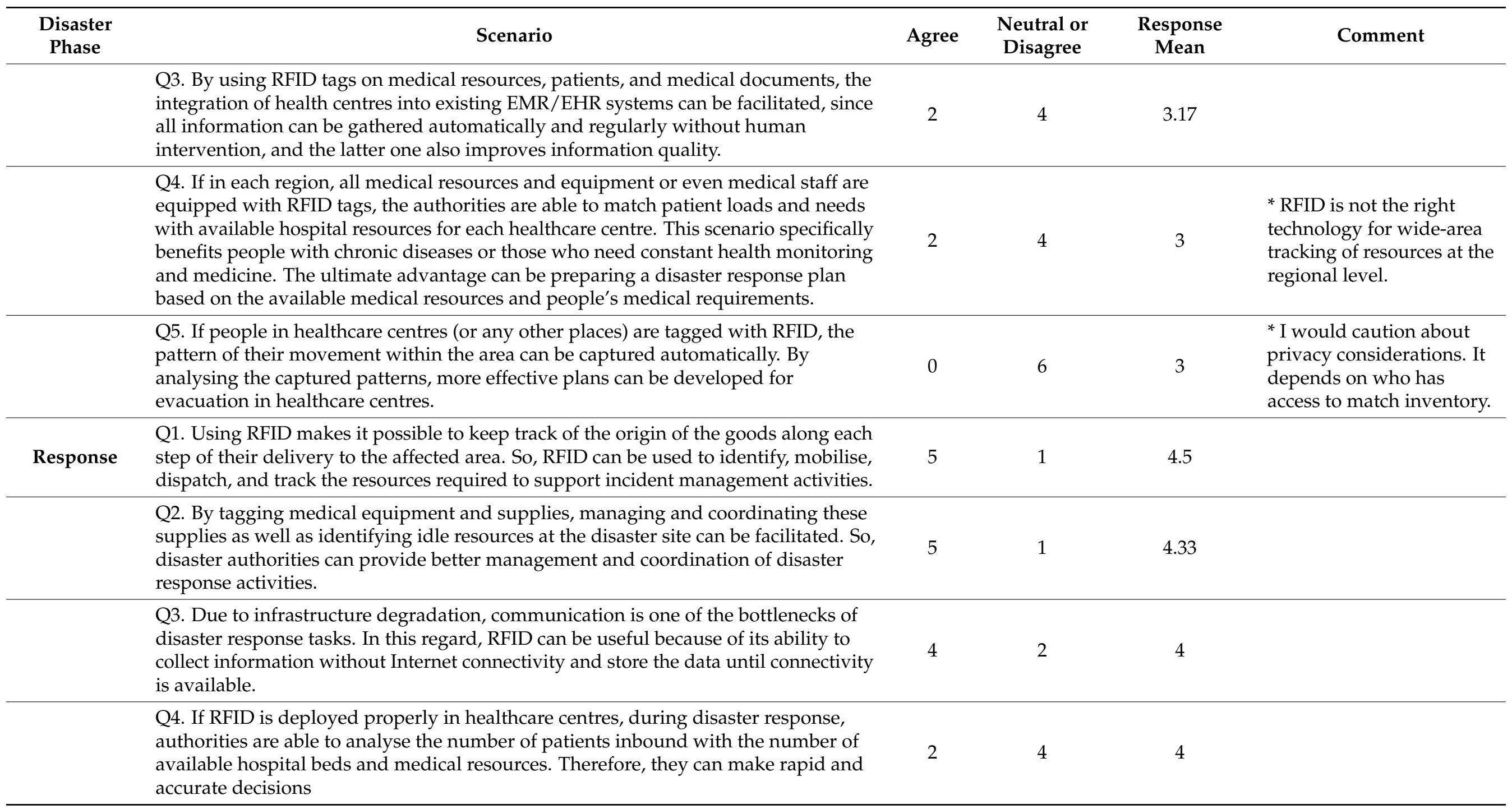


Table 4. Cont.

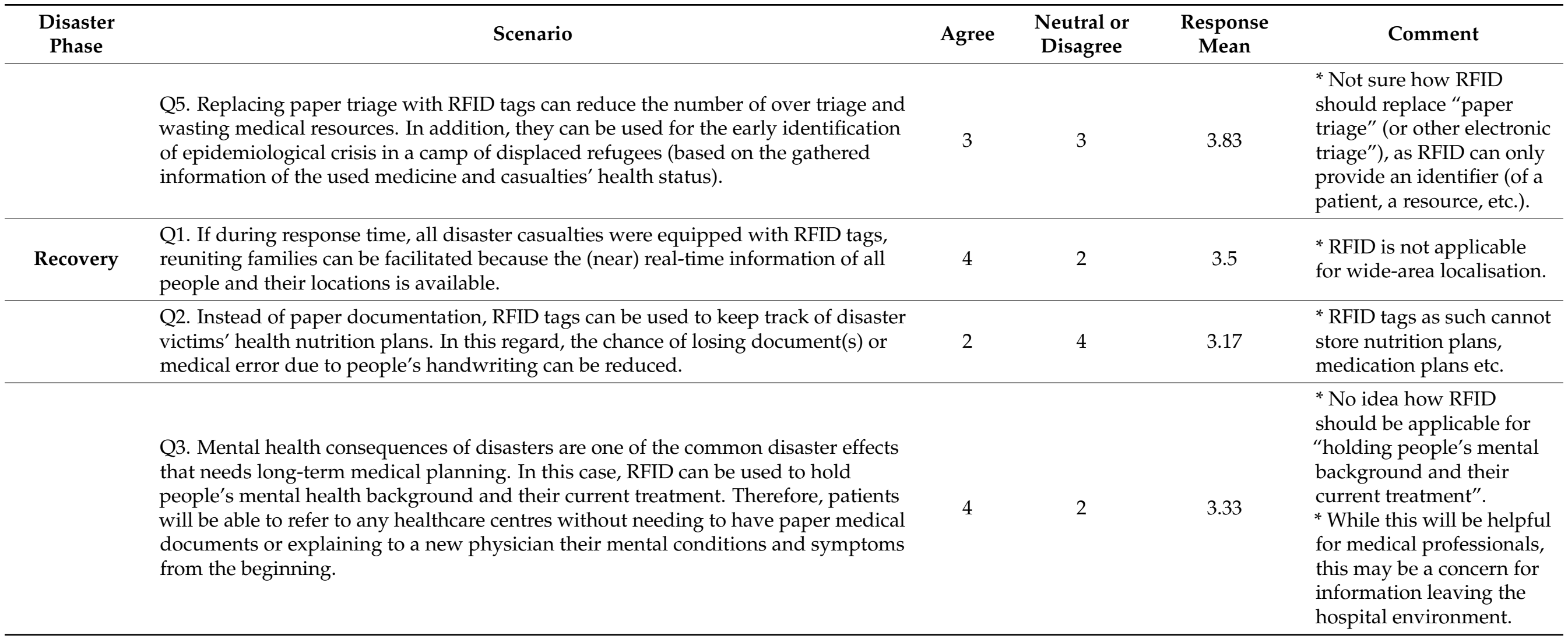




\section{Discussion}

Based on the Delphi results, the role of RFID was highlighted mostly in disaster response and recovery, although some RFID applications in disaster preparation were also supported.

Supply chain management (SCM) emerged as a major application for supporting disaster healthcare. RFID has proven successful for resource identification, tracking, and tracing, and facilitating coordination of the whole SC. Particular applications identified by this study include identifying and tracking medical resources, medicines, clinicians, first responders, and their accurate coordination in the response missions, determining idle resources, and maximising their utilisation during response activities.

RFID applications were identified as being potentially useful in disaster mitigation and preparedness phases, mostly for the timely identification of resources and tracking their usage. For example, authorities are able to check the inventory level of healthcare, distribution centres, and even pharmaceutical companies. In disaster mitigation and preparedness, such application may improve medical resources distribution and maintaining stockpile levels and may enhance the early detection of disease epidemics through monitoring the consumption of resources.

RFID can improve and facilitate data/information management. All involved parties in response missions can have near real-time information from disaster sites collected and stored on RFID embedded memory or transferred to a central repository. This feature helps different parties have common data from disaster sites that help enhance their cooperation and the quality of their decisions. This feature is useful even with disrupted network infrastructure in disaster regions, and RFID can be used as a standalone technology having the ability to capture data and save on embedded memories. When the connection between disaster-affected areas and other areas is re-established, the stored data can be uploaded to a central database and be accessible to authorised personnel.

RFID has been shown to be useful in epidemics [50,51] and recently in the COVID pandemic. People's health conditions can be monitored by physicians, saved on RFID tags, and sent to central databases, where further analysis can be performed, and any epidemic's trends can be captured based on accurate and timely data. RFID can also solve the over-triage problem in the aftermath of disasters if paper triage is replaced by RFID tags. Therefore, the problem of damage or lost paper triage can be resolved as all the triage information is available on RFID tags to pass through the medical chain. These applications turn all the static paper-based patient data into a dynamic electronic format that can be modified or transferred anytime and anywhere.

\subsection{Disaster Mitigation}

The Delphi panel strongly supported RFID for the availability of people's vital health information on an RFID tag. Although EHR is specifically designed for such requirements, its accessibility/availability during disasters is not guaranteed because of its dependency on different infrastructures such as communication and power. However, RFID tags and their readers can retrieve vital information from tags' embedded memory. One of the experts pointed to using a general-purpose smart card for core identification and healthcare data and another one mentioned the need for universally compatible readers.

The experts endorsed the RFID application for medical resources identification and localisation. The experts recommended implementing RFID together with an information system in the mitigation phase to provide opportunities such as the following:

- Automatically gathering resources' data and integrating them into a central repository;

- Improving the quality and accuracy of medical resources assessment;

- Analysing the medical resources usage pattern;

- $\quad$ Predicting associated future demands by identifying high-demand resources.

These points are useful in medical planning for disaster vulnerability analysis and for enhancing authorities' decision quality at different levels. Equipping medical resources with RFID can provide constant monitoring of the condition of healthcare centres and 
assessing their situations. This application can identify the efficiency or effectiveness of the healthcare activities in terms of utilised healthcare resources. Since RFID applications have proven successful in logistics, their integration from the mitigation phase can exploit their full potential in providing fast and effective response when disasters strike, since information for the medical products and equipment and their number for each healthcare centre is available on a real-time basis.

\subsection{Disaster Preparedness}

In this phase, using RFID for automatic data capturing could facilitate data sharing in healthcare from local to national levels. Delphi participants supported this technology for disaster preparedness. Although such data sharing on a large scale requires support and other technologies, such as cloud computing [52], RFID could be the building block as the basic requirement of data sharing is having precise, and preferably timely, data.

This automatic data-sharing application could help authorities have key information on the types and availability of medical resources. This can support the Just-in-Time (JIT) disaster plan concept in which the aim is to decrease the procedural and response times. Although the real application of JIT might be in disaster response, without proper preparedness, the deployment is most likely to fail. Delphi members accepted the concept of RFID utilisation for disaster plan purposes. The requirement for successfully implementing this JIT concept is having accurate and real-time information supported by RFID. If an information system is developed according to these features, taking advantage of the availability of the (near) real-time information and utilising the critical information can facilitate medical resources planning and the allocation of new resources to depots. In addition, disaster managers can access this information and, by correlating it with their possible additional datasets, they can exploit the full potential of the system. For example, by using this system and integrating it with people's demographic data at each level, authorities can match the inventory level of medicine with the population size and their demands in each region. Such a system provides disaster resilience for different societies and their communities.

RFID features in the facilitation of data sharing could contribute to the development of a warning system. Such a system has the potential and ability to identify epidemic outbreaks and forecast epidemiology disasters by analysing medical resources usage patterns. The Delphi participants found this application useful and desirable to have.

\subsection{Disaster Response}

In disaster response, RFID can serve different purposes. Among all scenarios, Delphi members gave the highest acceptance rate to RFID for victim identification and their tracking along the medical chain. Currently, there is no effective way of victim identification except by reading their paper triage or asking them or those accompanying them, which is a time-intensive and ineffective procedure and sometimes challenging, as injured or referral persons might be a child or unconscious and thus unable to communicate properly.

Tracking a casualties situation in the medical chain is almost impossible through the traditional way. However, RFID can address these challenges. RFID can help practitioners to identify victims easily and faster, decreasing the possible medical errors that result from chaotic disaster situations. By identifying the victims, a great percentage of medical errors related to their misidentification can be eliminated.

Large-scale resource management can be facilitated using RFID. Delphi participants found medical resource tagging useful in disaster response activities. If this tagging is employed properly in healthcare centres, preferably before disasters, it enables top managers to identify, mobilise, dispatch, and track the resources required to support incident management activities and track the origin of the goods along each step of their delivery to the affected area. This application facilitates the management and coordination of the supplies while identifying idle resources for their better reallocations as discussed in $[53,54]$ proposed self-adaptive systems. This equipped disaster authorities with rapid and accurate decisions, better management, and improved coordination of disaster response activities. 
It also enabled them to analyse the number of inbound patients, the number of available hospital beds, and the medical resources.

In the case of the unavailability of network infrastructure to disasters, first responders can use RFID tags to store the data until connectivity is re-established. In addition, by having timely information about the available medical resources at each healthcare centre, first responders are able to transport victims to the correct facility swiftly. This application along with victim identification can decrease a range of different kinds of errors.

\subsection{Disaster Recovery}

After disaster response, some activities require further follow-up. Delphi members identified RFID as a suitable technology to follow up victims' physical or mental health conditions. Since a victim's health condition information before the disaster and during the response time is available on the RFID tag, care disruption caused by disasters will be reduced. This application can benefit people with chronic diseases, and continuity of their care becomes possible, even after disasters. For the other casualties, RFID could provide the opportunity to healthcare providers to continuously monitor patients' health conditions, record and report vital signs, all of which leading to optimising care management and reducing consultation times and also possible healthcare errors.

Even if RFID tags started to be used from the disaster response phase, they could improve the follow-up health process and time efficiencies, as patients would not be required to explain fully their health conditions or problems in their first visits after disasters. If RFID tags are used in disaster response, it can enhance reuniting families. The peoples' names are entered into the tags during the response, and in the recovery phase, tracking their location becomes possible. Moreover, RFID tags can be used instead of papers for the identification of fatalities. This application can facilitate further related procedures such as tracking the victim's location and transferring them to their relatives.

\section{Conclusions}

Adopting RFID within DMC was inspired by its current usage for normal and emergency care, as it is postulated that RFID could play the same role in DMC. Incorporating RFID in disaster management can help to minimise the complexity of managing healthcare within DMC phases. By reducing human intervention and error and by providing quick and easy access to accurate and real-time data, RFID could improve post-operative care with the immediate goal of improving the quantity and quality of care and overall patient care. RFID applications can support disaster management and medicine, and its systematic integration into DMC could prepare healthcare organisations for disasters, facilitate disaster response activities, and support disaster recovery and mitigation tasks.

In this research, 35 potential scenarios of RFID applications for healthcare purposes within DMC and DEH were evaluated by a group of internationally recognised information system experts for disaster management using a Delphi method. The Delphi participants were experts in particular fields of e-health, disaster management, and disaster medicine.

The Delphi method was conducted in two rounds, and the results of each round were scrutinised in each disaster phase. Based on the Delphi results, the possibility of integrating RFID within all disaster phases can be deduced. Following the recommendations of [55], RFID can be integrated into the DMC before the disaster happens, from the mitigation phase, which could possibly exploit further opportunities as mentioned in [52]. This makes RFID one of the few technologies that can be implemented in all disaster phases for various goals, purposes, and applications due to its potential to bring integration and facilitating cooperation through its unique features.

RFID can be seen as a technology that, by automatically capturing data in real time or in pre-set periods, can provide good infrastructure and rich data. If these data are transferred to giant datasets on the cloud, they can provide a good infrastructure for big data and its analyses. If this trend starts from mitigation, it might detect any possible epidemics disasters from the early stage and significantly minimise their consequences. 
Additionally, RFID's automatic data capturing can feed peoples' EHR so that after disaster strikes, medical teams have access to a good amount of information about citizens' health backgrounds.

RFID possibly can also be a good fit for research purposes. One of the problems, especially in the disaster response, is that almost all the involved organisations try to provide healthcare support for disaster-affected communities, and data gathering is not undertaken properly. Yet if the data are gathered properly, their analysis can reveal so many hidden aspects of disasters and DMC activities such as the real bottleneck of response activities and probably their root causes, the performance of each participating organisation within DMC, and possibly the triggers that cause disasters. RFID may well be able to solve this problem due to its automatic data gathering features. If RFID is implemented properly during disaster response, at least some of the data can be gathered automatically and precisely in a way that may enable data analysts to extract some valuable information after disasters.

As one of the very few attempts of systematic investigation of the role of RFID in DMC, this research was conducted to get the fields' experts viewpoints on the role of RFID for facilitating healthcare purposes. This research was conducted through the Delphi method and has built a foundation of the most useful applications of RFID in DMC.

For future research, it is recommended to investigate these applications in more detail and from technical perspective and requirements. Additionally, within the recent few years, other auto-identification technologies such as IoT sensors and wearable devices have been considerably improved, making their usage favourable in healthcare and disaster healthcare. In this regard, it is recommended to investigate the role of IoT, state-of-the-art fabrication approaches of circuits on 3D freeform surfaces for IoT, as well as the manufacturing approaches for the high-frequency microwave devices.

Supplementary Materials: The following are available online at https:/ /www.mdpi.com/article/10 .3390/electronics10212621/s1, Supplementary Files S1: Delphi Questionnaire Round 1, Supplementary Files S2: Delphi Questionnaire Round 2.

Author Contributions: S.M. was the main investigator responsible for all aspects of research design, method, analysis, and dissemination. D.P. contributed to the research method and also participated in writing the manuscript. All authors have read and agreed to the published version of the manuscript.

Funding: This research received no external funding. The open access publication was partially supported by the Auckland University of Technology (AUT) Emerging Researcher Fund 2021.

Institutional Review Board Statement: The study was conducted according to the guidelines of Auckland University of Technology, and approved by the Auckland University of Technology Ethics Sub Committee (AUTEC). (Application number 17/111 and date of approval 19 June 2017).

Informed Consent Statement: Informed consent was obtained from all subjects involved in the study.

Data Availability Statement: The data presented in this study are available on request from the corresponding author. The data are not publicly available due to ethical restrictions.

Acknowledgments: The authors would like to thank Tony Norris for his support and contribution to the overall $\mathrm{PhD}$ research.

Conflicts of Interest: The authors declare no conflict of interest.

\section{References}

1. Maturana, C.; Scott, R.E.; Palacios, M. e-Health and the haddon matrix: Identifying where and how e-health can assist in disaster managment. In Global Telemedicine and eHealth Updates: Knowledge Resources; Lievens, M.J.F., Ed.; International Society for Telemedicine \& eHealth (ISfTeH): Grimbergen, Belgium, 2012; Volume 5, pp. 373-377.

2. World Helth Organization. Resolutions and Deliberations on eHealth; World Helth Organization: Switzerland, Geneva, 2005.

3. Madanian, S.; Norris, T.; Parry, D. Disaster eHealth: Scoping Review. J. Med. Int. Res. 2020, 22, e18310. [CrossRef] [PubMed]

4. Norris, A.C.; Martinez, S.; Labaka, L.; Madanian, S.; Gonzalez, J.J.; Parry, D. Disaster e-Health: A new paradigm for collaborative healthcare in disasters. In Proceedings of the 12th International Conference on Information Systems for Crisis Response and Management, Norway, Kristiansand, 24-27 May 2015. 
5. Baldini, G.; Braun, M.; Hess, E.; Oliveri, F.; Seuschek, H. The use of secure RFID to support the resolution of emergency crises. In Proceedings of the 43rd Annual 2009 International Carnahan Conference on Security Technology, Zurich, Switzerland, 5-8 October 2009; pp. 321-328.

6. Turcu, C.; Popa, V. An RFID-based system for emergency health care services. In Proceedings of the Advanced Information Networking and Applications Workshops, 2009. WAINA'09, International Conference on, Bradford, UK, 26-29 May 2009; pp. 624-629.

7. Kreps, G.L.; Neuhauser, L. New directions in eHealth communication: Opportunities and challenges. Patient Educ. Couns. 2010, 78, 329-336. [CrossRef] [PubMed]

8. Dohr, A.; Modre-Opsrian, R.; Drobics, M.; Hayn, D.; Schreier, G. The internet of things for ambient assisted living. In Proceedings of the Information Technology: New Generations (ITNG), 2010 Seventh International Conference on, Las Vegas, NV, USA, 12-14 April 2010; pp. 804-809.

9. Chen, M.; Gonzalez, S.; Leung, V.; Zhang, Q.; Li, M. A 2G-RFID-based e-healthcare system. Wirel. Commun. IEEE 2010, 17, 37-43. [CrossRef]

10. Bail, R.d.F.; Kovaleski, J.L.; da Silva, V.L.; Pagani, R.N.; Chiroli, D.M.d.G. Internet of things in disaster management: Technologies and uses. Environ. Hazards 2021, 1-21. [CrossRef]

11. Zafar, U.; Shah, M.A.; Wahid, A.; Akhunzada, A.; Arif, S. Exploring IoT Applications for Disaster Management: Identifying Key Factors and Proposing Future Directions. In Recent Trends and Advances in Wireless and IoT-Enabled Networks; Jan, M.A., Khan, F., Alam, M., Eds.; Springer International Publishing: Cham, Germany, 2019; pp. 291-309.

12. Madanian, S. Disaster e-Health Scope and the Role of RFID for Healthcare Purposes; Auckland University of Technology New Zealand: Auckland, New Zealand, 2019.

13. Madanian, S.; Madanian, A.S. The Role of Healthcare Information Systems Based on RFID Technology in Improving the Delivered Services in Healthcare Sector. In Proceedings of the Information System Conference, 1st National, Tehran, Iran, March 2015. Available online: https://www.researchgate.net/publication/272293623_The_Role_of_Healthcare_Information_Systems_Based_ on_RFID_Technology_in_Improving_the_Delivered_Services_in_Healthcare_Sector (accessed on 6 October 2021).

14. Wang, S.; Chen, W.; Ong, C.; Liu, L.; Chuang, Y.W. RFID application in hospitals: A case study on a demonstration RFID project in a Taiwan hospital. In Proceedings of the 39th Annual Hawaii International Conference on System Sciences (HICSS'06), Kauia, HI, USA, 4-7 January 2006; p. 184a.

15. Jokela, J.; Simons, T.; Kuronen, P.; Tammela, J.; Jalasvirta, P.; Nurmi, J.; Harkke, V.; Castren, M. Implementing RFID technology in a novel triage system during a simulated mass casualty situation. Int. J. Electron. Healthc. 2008, 4, 105-118. [CrossRef] [PubMed]

16. Fuhrer, P.; Guinard, D. Building a smart hospital using RFID technologies. ECEH 2006, 91, 131-142.

17. Rayens, M.K.; Hahn, E.J. Building consensus using the policy Delphi method. Policy Politics Nurs. Pract. 2000, 1, 308-315. [CrossRef]

18. Yao, W.; Chu, C.H.; Li, Z. The use of RFID in healthcare: Benefits and barriers. In Proceedings of the RFID-Technology and Applications (RFID-TA), 2010 IEEE International Conference on, Guangzhou, China, 17-19 June 2010; pp. 128-134.

19. Yang, H.; Yang, L.; Yang, S.H. Hybrid Zigbee RFID sensor network for humanitarian logistics centre management. J. Netw. Comput. Appl. 2011, 34, 938-948. [CrossRef]

20. Ahmed, A.; Sugianto, L.F. RFID in emergency management. In Auto-Identification and Ubiquitous Computing Applications; Symonds, J., Ayoade, J., Parry, D., Eds.; IGI Global: Hershey, PA, USA, 2009; pp. 137-155.

21. Van Gemert-Pijnen, J.E.; Nijland, N.; van Limburg, M.; Ossebaard, H.C.; Kelders, S.M.; Eysenbach, G.; Seydel, E.R. A holistic framework to improve the uptake and impact of eHealth technologies. J. Med. Internet Res. 2011, 13, e111. [CrossRef] [PubMed]

22. Ahmed, A.; Sugianto, L.F. Potential of RFID in emergency management: Task-technology fit perspective. In Proceedings of the 45th Hawaii International Conference on System Science (HICSS), Maui, HI, USA, 4-7 January 2012; pp. 4737-4745.

23. Aliyu, M.S.; Chizari, H.; Abdullah, A.H. Integrated sensor and RFID network node placement in disaster monitoring applications. In Proceedings of the RFID-Technologies and Applications (RFID-TA), 2013 IEEE International Conference on, Johor Bahru, Malaysia, 4-5 September 2013; pp. 1-5.

24. Chatfield, A.; Wamba, S.F.; Tatano, H. E-government challenge in disaster evacuation response: The role of RFID technology in building safe and secure local communities. In Proceedings of the System Sciences (HICSS), 2010 43rd Hawaii International Conference on System Science, Honolulu, HI, USA, 5-8 January 2010; pp. 1-10.

25. Kuo, F.; Chung-Jung, F.; Li, L.; Ming-Hui, J. The implement of RFID in emergency edicine. In Proceedings of the e-Health networking, Application and services, 2007 9th International Conference on, Taipei, Taiwan, 19-22 June 2007; pp. 125-130.

26. Lenert, L.A.; Palmer, D.A.; Chan, T.C.; Rao, R. An intelligent 802.11 triage tag for medical response to disasters. In Proceedings of the AMIA Aannual Symposium Proceedings, Washington, DC, USA, 22-26 October 2005; pp. 440-444.

27. Chan, T.C.; Killeen, J.; Griswold, W.; Lenert, L. Information technology and emergency medical care during disasters. Acad. Emerg. Med. 2004, 11, 1229-1236. [CrossRef]

28. Shamdani, A.; Nicolai, B. Applications of RFID in incident management. In Proceedings of the ICCGI 2012, The Seventh International Multi-Conference on Computing in the Global Information Technology, Venice, Italy, 24-29 June 2012 ; pp. 34-39.

29. Callaway, D.W.; Peabody, C.R.; Hoffman, A.; Cote, E.; Moulton, S.; Baez, A.A.; Nathanson, L. Disaster mobile health technology: Lessons from Haiti. Prehospital Disaster Med. 2012, 27, 148-152. [CrossRef] 
30. Brown, S.H.; Fischetti, L.F.; Graham, G.; Bates, J.; Lancaster, A.E.; McDaniel, D.; Gillon, J.; Darbe, M.; Kolodner, R.M. Use of electronic health records in disaster response: The experience of Department of Veterans Affairs after Hurricane Katrina. Am. J. Public Health 2007, 97, S136-S141. [CrossRef] [PubMed]

31. Baldini, G.; Hess, E.; Oliveri, F.; Seuschek, H.; Braun, M. Secure RFID for Humanitarian Logistics; INTECH Open Access Publisher: London, UK, 2011. Available online: https:/ / pubmed.ncbi.nlm.nih.gov/21659884/ (accessed on 6 October 2021).

32. Ingrassia, P.L.; Carenzo, L.; Barra, F.L.; Colombo, D.; Ragazzoni, L.; Tengattini, M.; Prato, F.; Geddo, A.; Della Corte, F. Data collection in a live mass casualty incident simulation: Automated RFID technology versus manually recorded system. Eur. J. Emerg. Med. 2012, 19, 35-39. [CrossRef]

33. Jorma, J.; Heli, L.; Janne, E.; Ville, H. Experiences of using a mobile RFID-based triage system. J. Aeronaut. Aerosp. Eng. 2013, 2, 117. [CrossRef]

34. O'Connor, M.E. In Haiti, RFID Brings Relief. Available online: www.rfidjournal.com/articles/view?7523 (accessed on 15 September 2021).

35. Wamba, S.F.; Ngai, E.W.T. Unveiling the potential of RFID-enabled intelligent patient management: Results of a Delphi study. In Proceedings of the 44th Hawaii International Conference on System Sciences, Kauai, HI, USA, 4-7 January 2011; pp. 1-10.

36. Okoli, C.; Pawlowski, S.D. The Delphi method as a research tool: An example, design considerations and applications. Inf. Manag. 2004, 42, 15-29. [CrossRef]

37. Hasson, F.; Keeney, S.; McKenna, H. Research guidelines for the Delphi survey technique. J. Adv. Nurs. 2000, 23, $1008-1015$.

38. Disaster eHealth Community of Interest. Available online: https://www.aut.ac.nz/study/study-options/engineering-computerand-mathematical-sciences/research/disaster-ehealth-community-of-interest (accessed on 23 March 2021).

39. Delbecq, A.L.; Van de Ven, A.H.; Gustafson, D.H. Group Techniques for Program Planning: A Guide to Nominal Group and Delphi processes; Scott Foresman: Glenview, IL, USA, 1975.

40. Penelope, M.M. Delphi: Myths and reality. J. Health Organ. Manag. 2003, 17, 37-52. [CrossRef]

41. Thangaratinam, S.; Redman, C.W.E. The Delphi technique. Obstet. Gynaecol. 2005, 7, 120-125. [CrossRef]

42. Hogarth, R.M. A note on aggregating opinions. Organ. Behav. Hum. Perform. 1978, 21, 40-46. [CrossRef]

43. Loughlin, K.G.; Moore, L.F. Using Delphi to achieve congruent objectives and activities in a pediatrics department. J. Med. Educ. 1979, 54, 101-106. [CrossRef] [PubMed]

44. McKenna, H.P. The selection by ward managers of an appropriate nursing model for long-stay psychiatric patient care. J. Adv. Nurs. 1989, 14, 762-775. [CrossRef] [PubMed]

45. McKenna, H.P. The Delphi technique: A worthwhile research approach for nursing? J. Adv. Nurs. 1994, 19, 1221-1225. [CrossRef]

46. Gliem, J.A.; Gliem, R.R. Calculating, Interpreting, and Reporting Cronbach's Alpha Reliability Coefficient for Likert-Type Scales. In Proceedings of the Midwest Research-to-Practice Conference in Adult, Continuing, and Community Education, Columbus, OH, USA, 8-10 October 2003; pp. 82-88.

47. Brown, J.D. The Cronbach alpha reliability estimate. JALT Test. Eval. SIG Newsl. 2002, 6, 17-19.

48. Reynaldo, A.; Santos, J. Cronbach's alpha: A tool for assessing the reliability of scales. J. Ext. 1999, 37, 1-5.

49. Nunnally, J.C. An Overview of Psychological Measurement. In Clinical Diagnosis of Mental Disorders: A Handbook; Wolman, B.B., Ed.; Springer: Boston, MA, USA, 1978; pp. 97-146.

50. Ho, H.J.; Zhang, Z.X.; Huang, Z.; Aung, A.H.; Lim, W.-Y.; Chow, A. Use of a Real-Time Locating System for Contact Tracing of Health Care Workers During the COVID-19 Pandemic at an Infectious Disease Center in Singapore: Validation Study. J. Med. Int. Res. 2020, 22, e19437. [CrossRef] [PubMed]

51. Weizman, Y.; Tan, A.M.; Fuss, F.K. Use of wearable technology to enhance response to the Coronavirus (COVID-19) pandemic. Public Health 2020, 185, 221-222. [CrossRef]

52. Madanian, S.; Parry, D. IoT, Cloud Computing and Big Data: Integrated Framework for Healthcare in Disasters. Stud Health Technol. Inf. 2019, 264, 998-1002. [CrossRef]

53. Johnson, K.; Cámara, J.; Sinha, R.; Madanian, S.; Parry, D. Towards Self-Adaptive Disaster Management Systems. In Proceedings of the ISCRAM 2021 Conference Proceedings-18th International Conference on Information Systems for Crisis Response and Management, Blacksburg, VA, USA, 23-26 May 2021; pp. 49-61.

54. Johnson, K.; Madanian, S.; Sinha, R. Graph-Theoretic Models of Resource Distribution for Cyber-Physical Systems of DisasterAffected Regions. In Proceedings of the 2020 46th Euromicro Conference on Software Engineering and Advanced Applications (SEAA), Kranj, Slovenia, 26-28 August 2020; pp. 521-528.

55. Sieben, C.; Scott, R.E.; Palacios, M. e-Health and Disaster Management Cycle. In Global Telemedicine and Ehealth Updates: Knowledge Resources; Jordanova, M., Lievens, F., Eds.; International Society for Telemedicine \& eHealth (ISfTeH): Grimbergen, Belgium, 2012. 